\title{
Novel association of MEN1 gene mutations with parathyroid carcinoma
}

\author{
LUIGIA CINQUE $^{1 *}$, ANGELO SPARANEO $^{2 *}$, FILOMENA CETANI $^{3}$, MICHELINA COCO $^{2}$, \\ CELESTE CLEMENTE $^{4}$, MASSIMILIANO CHETTA ${ }^{5}$, TERESA BALSAMO ${ }^{2}$, CLAUDIA BATTISTA $^{6}$, \\ ELIANA SANPAOLO ${ }^{1}$, ELENA PARDI $^{3}$, LEONARDO D'AGRUMA $^{1}$, CLAUDIO MARCOCCI $^{3}$, \\ EVARISTO MAIELLO ${ }^{7}$, GEOFFREY N. HENDY ${ }^{8,9}$, DAVID E.C. COLE ${ }^{10}$, \\ ALFREDO SCILLITANI $^{6}$ and VITO GUARNIERI ${ }^{1}$
}

\author{
${ }^{1}$ Department of Medical Genetics; ${ }^{2}$ Laboratory of Oncology, \\ IRCCS Casa Sollievo della Sofferenza Hospital, I-71013 San Giovanni Rotondo; ${ }^{3}$ Department of Clinical and \\ Experimental Medicine, Endocrine Unit 2, University Hospital of Pisa, I-56124 Pisa; ${ }^{4}$ Department of \\ Pathology, IRCCS Casa Sollievo della Sofferenza Hospital, I-71013 San Giovanni Rotondo; ${ }^{5}$ Laboratory of \\ Molecular Medicine and Genomics, University of Salerno, I-84081 Baronissi; Departments of ${ }^{6}$ Endocrinology and \\ ${ }^{7}$ Oncohematology, IRCCS Casa Sollievo della Sofferenza Hospital, I-71013 San Giovanni Rotondo, Italy; \\ ${ }^{8}$ Departments of Medicine, Physiology and Human Genetics, McGill University; ${ }^{9}$ Experimental Therapeutics and \\ Metabolism, McGill University Health Centre Research Institute, Montreal, QC H4A 3J1; ${ }^{10}$ Departments of \\ Laboratory Medicine and Pathobiology, Medicine and Genetics, University of Toronto, Toronto, ON M4N 3M5, Canada
}

Received September 22, 2016; Accepted December 23, 2016

DOI: $10.3892 / \mathrm{ol} .2017 .6162$

\begin{abstract}
Inactivating mutations of the multiple endocrine neoplasia 1 (MEN1) gene cause MEN1 syndrome, characterized by primary hyperparathyroidism (pHPT), and parathyroid and gastro-entero-pancreatic pituitary tumors. At present, only 14 cases of malignant parathyroid tumor have been associated with the syndrome, with 6 cases carrying an inactivating mutation of the MEN1 gene. The present study presents the case of a 48-year-old female who presented with multigland pHPT and multiple pancreatic lesions. The patient underwent surgery several times for the excision of parathyroid hyperplasia, carcinoma and adenoma. The MEN1 gene was screened, revealing three variants (in cis) at the intron/exon 3 boundary (IVS2-3G >C , c.497A > T and c.499G >T) detected on the DNA of the proband, not shared by her relatives. RNA sequencing revealed that the IVS2-3C>G variant caused the skipping of the exon 3 . Therefore, the present study reports on a novel rare
\end{abstract}

Correspondence to: Dr Vito Guarnieri, Department of Medical Genetics, IRCCS Casa Sollievo della Sofferenza Hospital, Viale Padre Pio, I-71013 San Giovanni Rotondo, Italy

E-mail: v.guarnieri@operapadrepio.it

"Contributed equally

Key words: MEN1, parathyroid carcinoma, multiple endocrine neoplasia association of MEN1 syndrome and parathyroid carcinoma. The reported splicing mutation was previously identified in subjects who always developed malignant lesions; thus, a possible genotype-phenotype association may be considered.

\section{Introduction}

Multiple endocrine neoplasia 1 (MEN1, MIM131100) syndrome is an endocrine autosomal dominant disorder occurring due to inactivating mutations of the MEN1 gene (1). Early symptoms of the syndrome are hypercalcemia and primary hyperparathyroidism (pHPT) associated with gastro-entero-pancreatic and pituitary tumors $(2,3)$. The MEN1 gene encodes menin, a co-transcription factor with numerous protein partners, including transcription factor jun-D (JunD) (4), nuclear factor- $\kappa \mathrm{B}$ (5) and SMAD family member 3 (6). In MEN1, the lesions of the parathyroid gland are benign adenoma or hyperplasia in $99 \%$ of cases and, to date, only 14 well-documented cases of parathyroid carcinoma (PC) and of an atypical adenoma associated with MEN1 syndrome have been reported, and in six of these cases, an inactivating mutation of the MEN1 gene was identified $(7,8)$.

$\mathrm{PC}$ is a rare cancer $(1 / 10,000$ of all cancer cases $)$ and constitutes $<1 \%$ of pHPT cases (9). It is an indolent malignancy and its pre-surgical identification may frequently represent a challenge due the variability at the clinical presentation and the absence of pathognomonic signs such as metastases $(10,11)$. PC may manifest sporadically or as part of HPT with jaw-tumor syndrome (HPT-JT, MIM145001), characterized by ossifying fibroma of the jaw and mandible, and renal and uterine lesions (12). HPT-JT is caused by inactivating mutations of 
the cell division cycle 73 gene, a tumor suppressor encoding a co-transcription factor, parafibromin, which is involved in RNA polymerase II transcription and chromatin remodeling (13).

The present study reports a novel MEN1 case affected by PC caused by a splicing mutation of the MENI gene, identified in cis with two other coding variants. Notably, data from previous studies reported that this splicing mutation was always previously identified in patients who developed varied malignancies (14-16), suggesting the hypothesis of a possible genotype with malignant phenotype association.

\section{Patients and methods}

Patient. A 48-year-old woman (Fig. 1A, II:4) presented in October 2004 at the Department of Endocrinology, Casa Sollievo della Sofferenza Hospital (San Giovanni Rotondo, Italy) with hypercalcemia (normal range, 8.1-10.4 mg/dl) and high parathyroid hormone (PTH) levels (normal range, $10-65 \mathrm{pg} / \mathrm{ml}$ ) (Table I), suggesting the diagnosis of pHPT. The functional enquiry was negative for fractures, nephrolithiasis and menstrual disorders. Bone mineral density determination revealed osteopenia. A 99Tc-sestamibi scan indicated two areas of radiotracer uptake: One behind the sternum manubria on the right side and the other at the level of the left thyroid lobe. Six months later (March 2005), in another hospital, a computed tomography (CT) abdominal scan was performed to investigate recurrent abdominal pain that spontaneously stopped, and two lesions of the head of the pancreas ( 8 and $14 \mathrm{~mm}$ in diameter, respectively) were identified. In association with pHPT, this suggested the diagnosis of MEN1 syndrome. At parathyroidectomy one year following the first diagnosis (October 2005), two nodular hyperplastic parathyroid glands were removed, with reduction of serum calcium and PTH occurring postoperatively. However, the following year (September 2006), serum calcium and PTH levels were again elevated (Table I). Serum gastrin $(86 \mathrm{pg} / \mathrm{ml}$; normal range, $0-100 \mathrm{pg} / \mathrm{ml})$, glucagon $(38 \mathrm{pg} / \mathrm{ml}$; normal range, $<60 \mathrm{pg} / \mathrm{ml})$ and prolactin $(8 \mathrm{ng} / \mathrm{ml}$; normal range, $<15 \mathrm{ng} / \mathrm{ml})$ levels were normal. En bloc excision of the parathyroid glands associated with the left thyroid lobe was performed, but a lesion behind the sternum was not located. The pathological diagnosis was suggestive of PC, and a micropapillary thyroid tumor $(1 \mathrm{~mm})$ was also identified in the excised left hemithyroid. The persistence of pHPT was evident following surgery. At three years following the initial diagnosis (June 2007), the patient was re-evaluated at the University of Pisa (Pisa, Italy), revealing elevated serum calcium and PTH levels (Table I). Neck ultrasound did not detect enlarged parathyroid glands, but $99 \mathrm{mTc}$-sestamibi imaging revealed an abnormal uptake at the lower pole of the right thyroid lobe. A CT scan of the neck confirmed a $1.5-\mathrm{cm}$ enlarged parathyroid gland in the right upper region of the mediastinum. The patient underwent parathyroidectomy and the $1.5-\mathrm{cm}$ right lower pole gland was removed. There was no evidence of local invasion at surgery. The histopathological diagnosis was of chief-cell parathyroid adenoma. The patient's family history was negative for endocrine disease and parathyroid cancer (Fig. 1A). Following surgery, PTH was undetectable, hypocalcemia developed, and treatment with calcium and calcitriol was commenced. At the
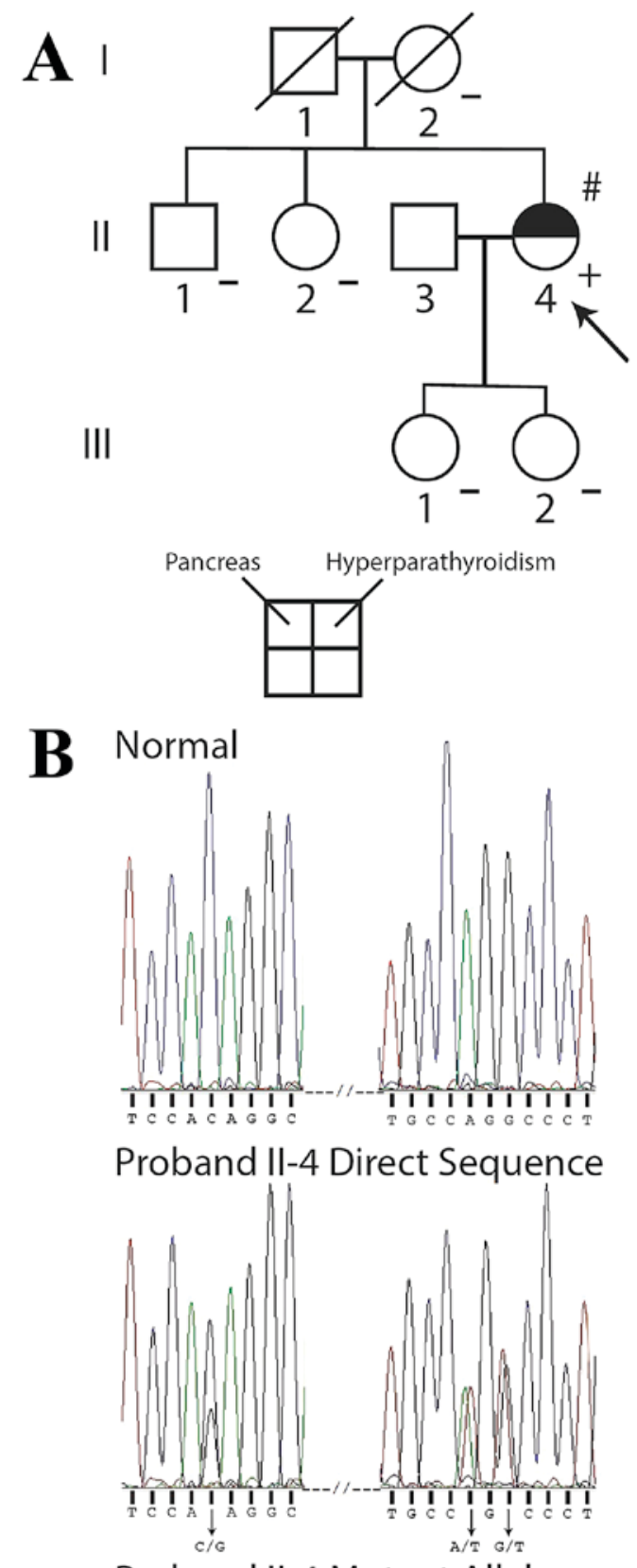

Proband II-4 Mutant Allele

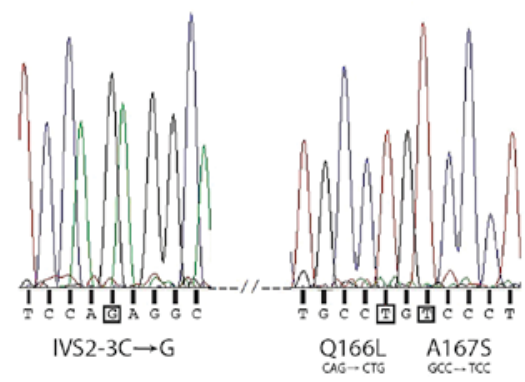

Figure 1. (A) Pedigree of the family under study. Clinical status is indicated by open symbols (unaffected or unknown) and filled symbols (affected). Filled quadrants indicate a diagnosis as explained in the inset legend. Histological diagnosis of carcinoma is indicated by \#. A diagonal slash mark through a symbol indicates deceased. Proband is indicated by the arrow. The presence (+) or absence (-) of a mutation in tested family members is presented. (B) Detection of a mutation in the multiple endocrine neoplasia 1 gene. Direct sequence analysis of the exon 3 genomic amplicon of proband I-4 (middle) revealed heterozygous IVS2-3C $>$ G, Q166L and A167S mutations compared with an unrelated healthy individual (top). All mutations are in cis, as confirmed by sequence analysis of the cloned mutant allele (bottom). The mutant nucleotides are boxed. 
Table I. Biochemistry and histology parameters at the time of each surgery.

\begin{tabular}{|c|c|c|c|c|c|}
\hline Date & $\mathrm{Ca}_{\mathrm{alb} \mathrm{adj}}{ }^{\mathrm{a}}, \mathrm{mg} / \mathrm{dl}$ & $\mathrm{PTH}^{\mathrm{b}}, \mathrm{pg} / \mathrm{ml}$ & 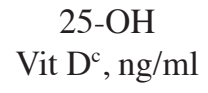 & $\begin{array}{c}\text { Calciuria } \\
24 \mathrm{~h}^{\mathrm{d}}, \mathrm{mg} / \mathrm{kg} / \text { day }\end{array}$ & $\begin{array}{l}\text { Parathyroid } \\
\text { histology }\end{array}$ \\
\hline Oct 2004 & 11.04 & 190 & 18.3 & 11.10 & $\mathrm{n} / \mathrm{a}$ \\
\hline Oct 2005 (1st PTX) & 11.72 & 210 & & & 2 hyperplasias \\
\hline Sep 2006 (2nd PTX) & 11.84 & 160 & & & Carcinoma \\
\hline June 2007 (3rd PTX) & 12.83 & 107 & & & Adenoma \\
\hline
\end{tabular}

${ }^{\mathrm{a} N o r m a l ~ r a n g e, ~ 8.1-10.4 ~ m g / d l ; ~}{ }^{\mathrm{b}}$ normal range, $10-65 \mathrm{pg} / \mathrm{ml}$; ${ }^{\mathrm{c}}$ normal range, $20-40 \mathrm{ng} / \mathrm{ml}$; ${ }^{\mathrm{d}}$ normal value, $4.00 \mathrm{mg} / \mathrm{kg} / \mathrm{day}$. Glucose, insulin, gastrin, glucagon, prolactin, growth hormone and insulin-like growth factors were normal. $\mathrm{Ca}_{\mathrm{alb}}$ adj , calcium albumin adjustment; PTH, parathyroid hormone; PTX, parathyroidectomy; 25-OH Vit D, 25-hydroxy vitamin D; n/a, not applicable.

most recent evaluation (11 years following the first diagnosis, in 2015), serum calcium was normal and PTH remained undetectable. There has been no change in the pancreatic lesions detectable by abdominal CT, nor the appearance of pituitary lesions has been observed in magnetic resonance imaging scans in the 11-year follow-up.

Genetic screening. DNA was extracted from peripheral blood of the patient and relatives, and it was PCR amplified and directly sequenced according to previous protocol (17). DNA from formalin-fixed paraffin-embedded tumor tissues (carcinoma obtained in September 2006 and adenoma in June 2007) was extracted, as previously described (11) and loss of heterozygosity ( $\mathrm{LOH}$ ) at the MEN1 genetic locus (chromosome 11q13.1) was assessed as described previously (18). Subcloning of exon 3 was performed using the Strataclone PCR Cloning kit (Agilent Technologies, Inc., Santa Clara, CA, USA) following the manufacturer's protocol.

MEN1 splicing mutation assay. Blood was collected in a PAXgene ${ }^{\circledR}$ Blood RNA tube (BD Biosciences, Franklin Lakes, NJ, USA), RNA was extracted using a PAXgene ${ }^{\circledR}$ Blood RNA kit (Thermo Fisher Scientific, Inc., Waltham, MA, USA) and reverse transcribed using a Superscript III First-Strand Synthesis SuperMix (Thermo Fisher Scientific, Inc.). Corresponding complementary DNA (cDNA) was amplified in a $50 \mu \mathrm{l}$ reaction containing: $5 \mu \mathrm{l} 10 \mathrm{X}$ AmpliTaq Gold Polymerase buffer, $5 \mu \mathrm{ldNTP}(25 \mathrm{mM}), 20 \mathrm{pmol}$ (final concentration) specific exon forward/reverse primers (Table II) and $1 \mu \mathrm{l}$ AmpliTaq Gold Polymerase (all Thermo Fisher Scientific, Inc.). PCR cycling conditions were as follows: Initial denaturation at $95^{\circ} \mathrm{C}$ for $10 \mathrm{~min} ; 25$ cycles of $95^{\circ} \mathrm{C}$ for $30 \mathrm{sec}, 55^{\circ} \mathrm{C}$ for $30 \mathrm{sec}$ and $72^{\circ} \mathrm{C}$ for $30 \mathrm{sec}$; final extension of $72^{\circ} \mathrm{C}$ for $7 \mathrm{~min}$. Amplicons were purified from the gel using an Illustra GFX PCR DNA and Gel Band Purification kit (GE Healthcare Life Sciences, Chalfont, UK) and directly sequenced using a Big Dye Terminator v1.1 Cycle Sequencing kit (Thermo Fisher Scientific, Inc.).

cDNA expression vectors. Mutations were introduced into a pCMV-Tag2B expression vector (Stratagene; Agilent Technologies, Inc.) carrying the 5' FLAG-tagged human menin cDNA as described previously (19). Reactions containing no DNA were added as internal control.
Mutagenesis primers are presented in Table III. Colony PCR was performed with specific T7 and T3 primers (5'-TAATACGACTCACTATAG-3' and 5'-AATTAACCC TCACTAAAG-3', respectively) in a $25 \mu \mathrm{l}$ PCR volume containing 2.5 $\mu \mathrm{l}$ 10X AmpliTaq Gold Polymerase buffer, $2.5 \mu \mathrm{ldNTP}(25 \mathrm{mM}), 10 \mathrm{pmol}$ (final concentration) forward and reverse primers, and $1 \mu \mathrm{l}$ AmpliTaq Gold Polymerase. PCR cycling conditions were as follows: Initial denaturation at $95^{\circ} \mathrm{C}$ for $10 \mathrm{~min} ; 25$ cycles of $95^{\circ} \mathrm{C}$ for $30 \mathrm{sec}, 60^{\circ} \mathrm{C}$ for $30 \mathrm{sec}$ and $72^{\circ} \mathrm{C}$ for $30 \mathrm{sec}$; final extension of $72^{\circ} \mathrm{C}$ for $7 \mathrm{~min}$. PCR purification and sequencing were as described above, and led to the identification of mutant clones. Midi-preps were generated using a Plasmid Midi kit (Qiagen, Inc., Valencia, CA, USA).

Cell culture and western blotting. Human embryonic kidney (HEK293) cells (European Collection of Authenticated Cell Cultures, Public Health England, UK) were cultured in Dulbecco's modified Eagle's medium/Ham's F12 medium supplemented with $10 \%$ fetal bovine serum, $1 \%$ penicillin/streptomycin (all Sigma-Aldrich; Merck Millipore, Darmstadt, Germany), and incubated at $37^{\circ} \mathrm{C}$ in a humidified, $5 \% \mathrm{CO}_{2}$ incubator. Wild-type and mutant vectors were transfected in three replicates using the FuGENE ${ }^{\circledR}$ transfection reagent (Promega Corporation, Madison, WI, USA) according to the manufacturer's protocol. For each experiment, the HEK293 cells used had a passage number $<10$. At $48 \mathrm{~h}$ following transfection, total cell proteins were extracted in radioimmunoprecipitation assay buffer supplemented with a protease inhibitor cocktail (Complete ${ }^{\mathrm{TM}}$ EDTA-Free; Roche Applied Science, Penzburg, Germany); protein concentration was determined using the Bio-Rad Protein Assay (Bio-Rad Laboratories, Inc., Hercules, CA, USA) and $80 \mu \mathrm{g}$ of protein were separated by $10 \%$ SDS-PAGE. Following electrophoresis, proteins were electrotransferred to polyvinylidene difluoride membranes (Merck Millipore). Blotting was performed overnight at $4{ }^{\circ} \mathrm{C}$ using a mouse anti-menin monoclonal antibody (1:500; \#sc374371; Santa Cruz Biotechnology, Inc., Dallas, TX, USA), anti-FLAG rabbit polyclonal antibody $(1: 5,000 ; \# 2368)$ or an anti- $\beta$-tubulin rabbit monoclonal antibody $(1: 5,000$; \#2146, both from Cell Signaling Technology, Inc., Inc., Danvers, MA, USA). Horseradish peroxidase-conjugated goat anti-mouse or goat anti-rabbit immunoglobulin G (\#sc2005 or \#sc2004, 
Table II. Exonic primers for RT, Tm and size of the polymerase chain reaction product.

\begin{tabular}{lcc}
\hline Amplicon & $5^{\prime}$ to 3 ' sequence & Tm, ${ }^{\circ} \mathrm{C}$ \\
\hline RT-EX3 forward & ATGGGGCTGAAGGCCGCCCA & 55 \\
RT-EX3 reverse & TGCTGCAGCTGCAGAAGCTC & 782 \\
\hline
\end{tabular}

Tm, annealing temperature; RT-EX3, reverse transcription exon 3.

Table III. Mutagenesis primers.

Amplicon

Q166L forward

Q166L reverse

A167S forward

A167S reverse

Q166-A167 forward

Q166-A167 reverse $5^{\prime}$ to $3^{\prime}$ sequence ${ }^{a}$

${ }^{\mathrm{a}}$ Mutated bases are underlined.

respectively; 1:5,000; Santa Cruz Biotechnology, Inc.) was used as the secondary antibody and incubated for $1 \mathrm{~h}$ at room temperature. The HRP signal was detected using a chemiluminescent substrate (Clarity Western ECL, Bio-Rad Laboratories, Inc.) and for quantitative measurements, films were scanned using densitometry and lanes corresponding to proteins were analyzed using ImageJ (version $1.44 \mathrm{p}$; National Institutes of Health, Bethesda, MD, USA; http://imagej.nih. gov/ij/).

Three-dimensional (3D) mutation prediction. Menin 3D structures were modeled using Phyre2 (Protein Homology Fold Recognition Server; www.sbg.bio.ic.ac.uk/phyre2/) (20). The analyses were implemented using Phyre investigator, a workbench analysis tool, which provides additional features to investigate models created with Phyre2. All *.pdb files generated from Phyre 2 were loaded and visualized with ChemDraw software (version 8; Cambridge Software; PerkinElmer, Inc., Waltham, MA, USA).

Hematoxylin and eosin staining. Hematoxylin and eosin staining was performed as previously described (21).

\section{Results}

Molecular screening. Molecular screening of the MEN1 gene revealed the presence of three variants. Two were novel nucleotide changes in exon 3 (c.497A>T/p.Q166L and c.499G>T/p. A167S) affecting two adjacent codons and the third was a previously identified intronic variant (c.446-3C $>$ G/IVS2-3C $>$ G) at the 5 'end of exon 3 (22,23). Screens of available relatives (two daughters, one brother, one sister and the mother) were negative for the presence of these variants (Fig. 1A). Subsequent cloning of the amplicon and sequencing revealed all three

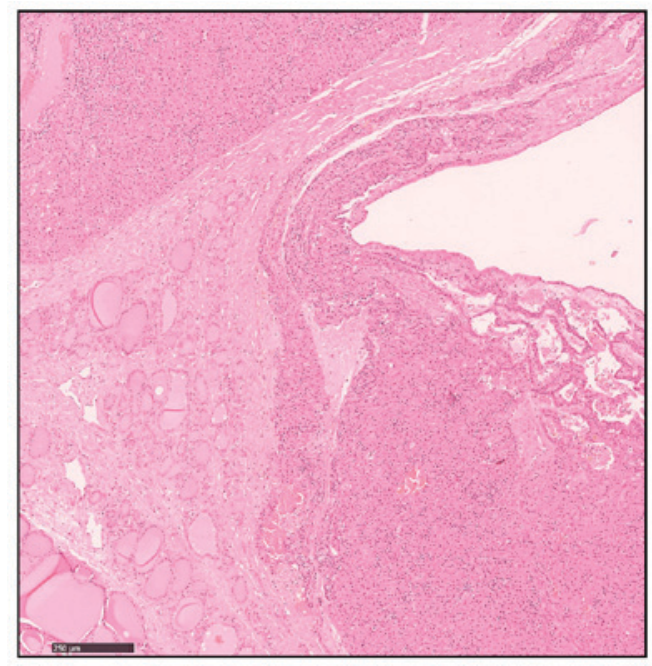

Figure 2. Characteristic neoplastic invasion of parathyroid carcinoma cells into adjacent vessels and gross invasion of the surrounding thyroid tissue. Staining, hematoxylin and eosin; magnification, $x 20$.

variants to be in cis (Fig. 1B). No LOH was detected in PC tumor tissue.

Pathological findings of PC. In 2004, the World Health Organization (WHO) Classification Criteria of Tumors of Endocrine Organs defined PC as being characterized by unequivocal vascular invasion, perineural invasion, gross invasion into adjacent anatomic structures and metastasis (24). Original hematoxylin and eosin-stained tissue sections of parathyroid lesions were reviewed, and microscopic evaluation revealed parathyroid lesions with ossifying cells and intratumoral fibrous bands exhibiting capsular penetration, invasion of surrounding vessels and gross 

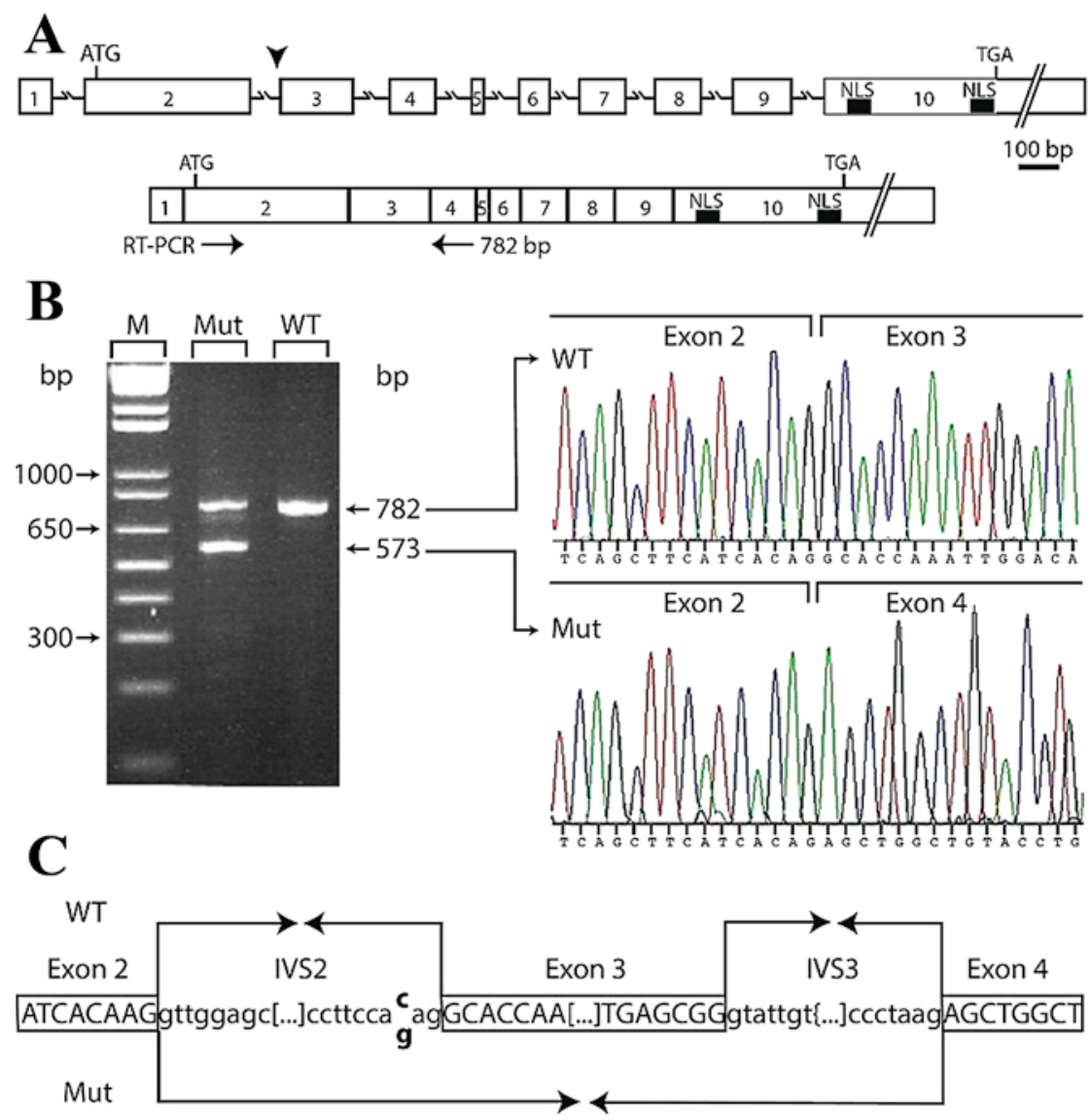

Figure 3. Effect of the MEN1 IVS2-3C > G mutation at the mRNA level. (A) Schematic of the $M E N 1$ gene and menin mRNA. The 10 gene exons with introns (not drawn to scale) are shown with the initiation codon (ATG) in exon 2, the acceptor splice-site mutation at the intron $2 /$ exon 3 boundary (black arrow), the two NLSs, and the stop codon (TGA) in exon 10. The menin mRNA includes exons 1-10 and the positions of primers used in exons 2 and 4 (RT-PCR product, $782 \mathrm{bp}$ ) are presented. (B) Gel electrophoresis of RT-PCR products following amplification of menin complementary DNA from blood RNA of individual II-4 of family 2 (Mut) or an unrelated normal individual (WT). DNA marker sizes are shown on the left. To the right, direct sequence analysis of the 782-bp WT and the 573-bp Mut products are presented. (C) The WT species corresponds to a product in which exon 2 is correctly spliced to exon 3, whereas the Mut species corresponds to an exon 2/exon 4 product in which exon 3 (209 bp) has been spliced out. MEN1, multiple endocrine neoplasia 1; mRNA, messenger RNA; NLS, nuclear localization signal; RT-PCR, reverse transcription-polymerase chain reaction; mut, mutated; WT, wild-type; M, marker.

invasion of adjacent thyroid parenchyma, thus leading to the diagnosis of PC (Fig. 2). Conversely, neither vascular or perineural space invasion nor capsular infiltration were observed in the case of encapsulated parathyroid neoplasm exhibiting morphological features satisfying diagnostic criteria of parathyroid adenoma (secondary lesion excised from the proband; data not shown).

Messenger RNA (mRNA) assay. cDNA sequencing revealed that the intronic IVS2-3G $>C$ variant impaired the correct splicing mechanism and lead to the skipping of exon 3 and the fusion of exon 2 with exon 4 . This led to the production of an alternatively spliced MEN1 mRNA with a premature stop codon at residue 162 (p.G149Efs*13; Fig. 3).

Functional assays. Western blot analysis of crude lysates extracts from HEK293 cells transfected with wild-type and mutant vectors revealed that the A167S variant was as well expressed as the wild-type, whereas the Q166L and the double mutant (Q166L/A167S) variants were almost totally unexpressed, in keeping with the mutant control, R415X (Fig. 4A).

The effect of the double variant Q166L/A167S on the structure of the protein was examined (Fig. 4B panel d).
3D modeling was performed using Phyre 2 and $81 \%$ of the residues were modeled at an accuracy of $>90 \%$. A comparison between wild-type MEN1 protein and double-mutant protein (Q166L-A167S) revealed a reduction in the pocket domain surface involved in binding to mixed-lineage leukemia 1 (MLL) and JunD (yellow circle), in addition to a potential displacement of the region encompassing amino acids 392-401 (light blue circle) involved in suppressor of variegation 3-9 homolog 1 interaction. The potential impact of the single mutations p.Q166L and p.A167S, and the two combined on protein folding was investigated (Fig. 4B). In all cases, a reduction of the MLL2/JunD pocket surface as well as a displacement of the amino acids 392-401 was observed, consistent with a possible cooperative effect of the mutations.

\section{Discussion}

For $>30$ years, guidelines from Shantz and Castleman agreed that capsular and vascular penetration, broad fibrous bands accompanied by trabecular pattern and mitotic activity were specific in distinguishing parathyroid adenoma from carcinoma (25). Unequivocal perineural, vascular, capsular invasion and growth into the adjacent tissues were further indicated by 


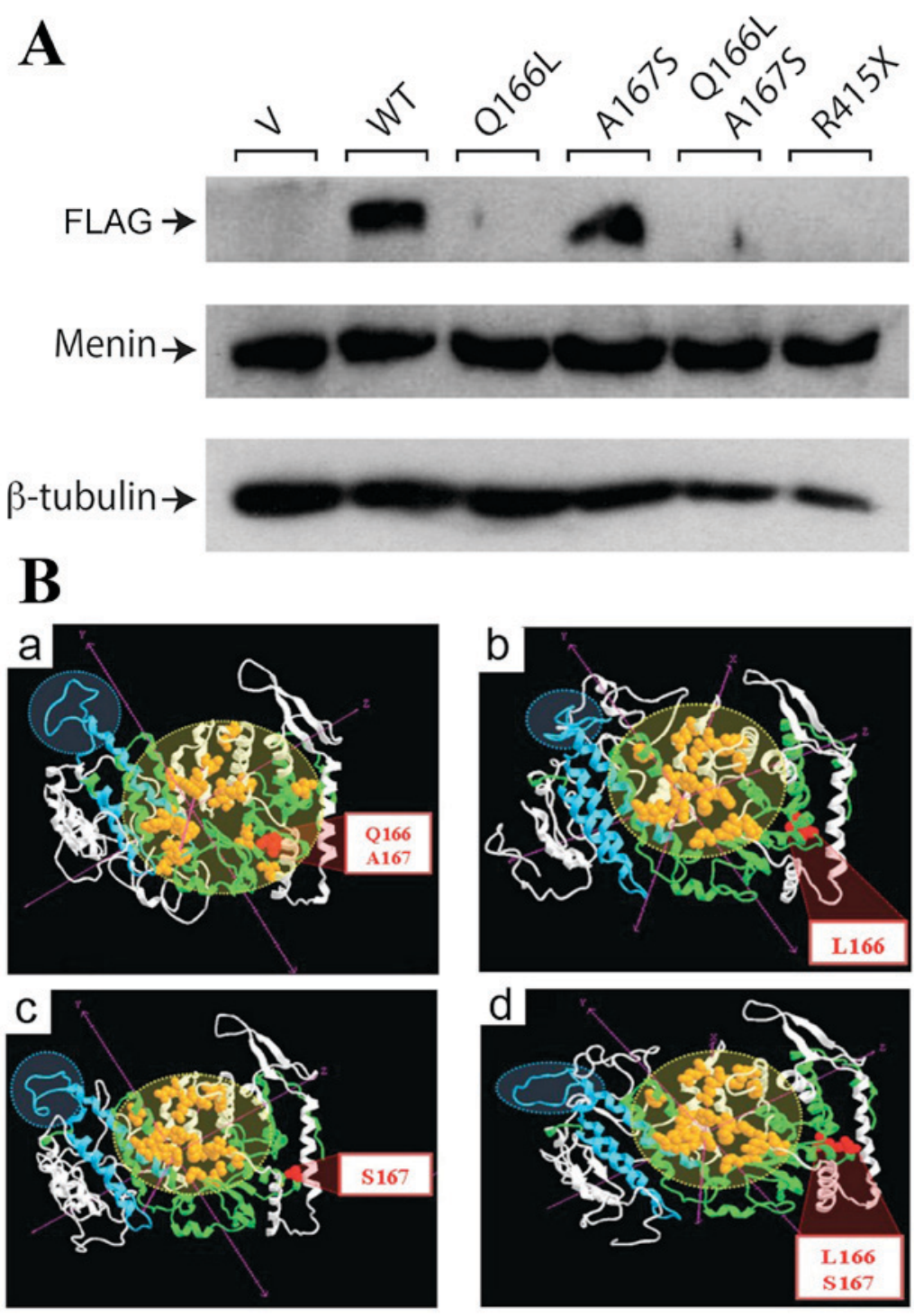

Figure 4. (A) Menin Q166L and Q166L/A167S missense mutants are poorly expressed relative to WT menin. FLAG-tagged menin constructs (including the R415X poorly expressed control) were transfected into HEK293 cells, and after $48 \mathrm{~h}$, cell lysates were subjected to western blot analysis with anti-FLAG, anti-Menin and anti- $\beta$-tubulin antibodies. In contrast to the aforementioned mutants, the A167S single mutant was as well expressed as WT menin. (B) Predicted three-dimensional structures of menin, wild-type (a) and mutant proteins (b-d). Panel a represents the wild-type form with the pocket domain (Asp136, Asp153, Leu177, Asp180, Pro245, Leu257, Tyr276, Met278, Asp285, Leu286, Glu288, Tyr319, Met322, Tyr323, Phe328, Glu363 and Glu366) highlighted in orange, the JunD binding domain (amino acids 1-40 and 139-242) in green and the suppressor of variegation 3-9 homolog 1 interaction domain (amino acids 360-445) in light blue. The point mutations Q166L and A167S are colored red. Panels b, c and d represent the protein structure inferred by inserting one or the other variant, or the two, respectively. In all cases, a decrease of the pocket domain surface involved in binding to the mixed-lineage leukemia 1 and JunD proteins was predicted. V, vector; WT, wild-type; JunD, transcription factor jun-D.

the WHO in 2004, and at present they represent the standard criteria for diagnosis of this type of pathology (24). Although an association of MEN1 syndrome and parathyroid carcinoma is rare, the case presented in the present study fulfilled all the aforementioned criteria.

With regards to the 14 previous cases of PC and MEN1, two recent meta-analyses reported 12 cases of PC associated with MEN1 syndrome in the last 40 years (prevalence of $0.28 \%$ ) (7), and 2 PCs and 1 case of atypical parathyroid adenoma in 242 MEN1 patients in another study at a higher frequency (0.8\%) (8). A total of 6 MEN1 genetic mutations out of 14 PC cases were identified. In 2 cases, the clinical description provided no indications concerning the invasion of surrounding tissues, and only 5 cases manifested metastasis or recurrence (chest wall, mediastinum, lungs and thyroid gland), whereas the remaining 9 cases exhibited an unremarkable course following surgery (8).

The novel sporadic association of PC and MEN1 syndrome presented in the present study was caused by a known splicing mutation of the MEN1 gene. Although this mutation has been previously reported (15), to the best of our knowledge, the present study reveals for the first time that the IVS2-3G $>C$ variant exerts a deleterious effect in removing the exon 3-encoded amino acid sequence, which is important, for example, for the menin-SMAD3 interaction and the cytostatic actions of transforming growth factor- $\beta$ (6). The other variants, c.497A $>$ T and c.499G $>T$, occur in cis with the splice-site mutation in the proband; however, their concurrent inheritance is not established and de novo occurrence cannot be ruled out. The present study examined the potential for the p.166L 
and p.167S variants to be functionally impaired by using transient transfection experiments, bioinformatics analysis and structural modelling. The majority of menin missense mutants studied to date are unstable, as they are targeted to the proteasome and are expressed poorly (26). In the present study, whereas the p.167S variant was as well expressed as wild-type menin when transiently transfected in HEK293 cells, p.166L alone or the p.166L167S double mutant were not (Fig. 4A). Additionally, three in silico bioinformatic analysis tools predicted the two mutations to be deleterious (data not shown). Furthermore, 3D structural modelling predicted that the binding of each mutant to MLL and JunD cofactors that occurs in the 139-242 amino acid sequence $(4,27)$ may be altered relative to wild-type menin (Fig. 4B).

Notably, the present study also reported an unusual association between PC and micropapillary thyroid cancer. A previous detailed metanalysis encountered only 21 cases of thyroid diseases associated with parathyroid malignancy in the last 10 years (28). In the present case, since the micropapillary lesion was of $1 \mathrm{~mm}$ and the en bloc resection of the thyroid lobe contributed to the eradication of the cancer, the patient received no further follow-ups for thyroid disease.

An important point concerns the unusual association of the IVS2-3C $>$ G splicing mutation and malignant tumors. Data from previous studies has reported the IVS2-3C $>$ G mutation in MEN1 syndrome three times, and it is always associated with malignant lesions. These include a family with 'malignant thymoma and enteropancreatic malignancy' in the same branch (14), a family with an unspecified carcinoid (15) and a family with recurrent thymic carcinoid (16); the present study reports the association with a malignant parathyroid lesion. Considering that malignancies, including carcinoids, are infrequent $(<3 \%)$ in MEN1 cases (29), a possible correlation between this splicing mutation and the malignant behavior of the MEN1 disease course and its associated tumors must not be excluded. Although it requires further in-depth studies, it may aid the management of patients carrying this specific mutation.

In conclusion, the present study reports a novel association between MEN1 gene mutations and PC, highlighting a potential correlation between the IVS3-2G>C MEN1 mutation and malignancy. Finally, with the identification of functionally tested novel variants, additional MEN1 gene mutations have been observed.

\section{Acknowledgements}

The authors gratefully acknowledge the family participating in the present study. This research was supported by the Ricerca Corrente 2007 and GR Familia Project (grant no. 2011-02351489) funding granted by the Italian Ministry of Health, by a Canadian Institutes of Health Research Operating Grant (grant no. MOP142269) and by the '5x1,000' voluntary contributions.

\section{References}

1. Chandrasekharappa SC, Guru SC, Manickam P, Olufemi SE, Collins FS, Emmert-Buck MR, Debelenko LV, Zhuang Z, Lubensky IA, Liotta LA, et al: Positional cloning of the gene for multiple endocrine neoplasia-type 1. Science 276: 404-407, 1997.

2. Wermer P: Genetic aspects of adenomatosis of endocrine glands. Am J Med 16: 363-371, 1954
3. TrumpD, Farren B, Wooding C, Pang JT, Besser GM, Buchanan K, Edwards CR, Heath DA, Jackson CE, Jansen S, et al: Clinical studies of multiple endocrine neoplasia type 1 (MEN1). QJM 89: 653-669, 1996

4. Agarwal SK, Guru SC, Heppner C, Erdos MR, Collins RM, Park SY, Saggar S, Chandrasekharappa SC, Collins FS, Spiegel AM, et al: Menin interacts with the AP1 transcription factor JunD and represses JunD-activated transcription. Cell 96: 143-152, 1999.

5. Heppner C, Bilimoria KY, Agarwal SK, Kester M, Whitty LJ, Guru SC, Chandrasekharappa SC, Collins FS, Spiegel AM, Marx SJ and Burns AL: The tumor suppressor protein menin interacts with NF-kappaB proteins and inhibits NF-kappaB-mediated transactivation. Oncogene 20: 4917-4925, 2001.

6. Kaji H, Canaff L, Lebrun JJ, Goltzman D and Hendy GN: Inactivation of menin, a Smad3-interacting protein, blocks transforming growth factor type beta signaling. Proc Natl Acad Sci USA 98: 3837-3842, 2001.

7. Singh Ospina N, Sebo TJ, Thompson GB, Clarke BL and Young WF Jr: Prevalence of parathyroid carcinoma in 348 patients with multiple endocrine neoplasia type 1-case report and review of the literature. Clin Endocrinol (Oxf): Dec 31, 2014 (Epub ahead of print).

8. Christakis IA, Busaidy NL, Cote GJ, Williams MD, Hyde SM, Silva Figueroa AM, Kwatampora LJ, Clarke CN, Qiu W, Lee JE and Perrier ND: Parathyroid carcinoma and atypical parathyroid neoplasms in MEN1 patients; A clinico-pathologic challenge. The MD Anderson case series and review of the literature. Int J Surg 31: 10-16, 2016

9. Marcocci C, Cetani F, Rubin MR, Silverberg SJ, Pinchera A and Bilezikian JP: Parathyroid carcinoma. J Bone Miner Res 23: 1869-1880, 2008

10. Campennì A, Ruggeri RM, Sindoni A, Giovinazzo S, Calbo L, Ieni A, Monaco M, Tuccari G, Benvenga S and Baldari S: Parathyroid carcinoma as a challenging diagnosis: Report of three cases. Hormones (Athens) 11: 368-376, 2012.

11. Guarnieri V, Battista C, Muscarella LA, Bisceglia M, de Martino D, Baorda F, Maiello E, D'Agruma L, Chiodini I, Clemente C, et al: CDC73 mutations and parafibromin immunohistochemistry in parathyroid tumors: Clinical correlations in a single-centre patient cohort. Cell Oncol (Dordr) 35: 411-422, 2012.

12. Carpten JD, Robbins CM, Villablanca A, Forsberg L, Presciuttini S, Bailey-Wilson J, Simonds WF, Gillanders EM, Kennedy AM, Chen JD, et al: HRPT2, encoding parafibromin, is mutated in hyperparathyroidism-jaw tumor syndrome. Nat Genet 32: 676-680, 2002.

13. Newey PJ, Bowl MR and Thakker RV: Parafibromin-functional insights. J Int Med 266: 84-98, 2009.

14. Burgess JR, Nord B, David R, Greenaway TM, Parameswaran V, Larsson C, Shepherd JJ and Teh BT: Phenotype and phenocopy: The relationship between genotype and clinical phenotype in a single large family with multiple endocrine neoplasia type 1 (MEN 1). Clin Endocrinol (Oxf) 53: 205-211, 2000.

15. Cardinal JW, Bergman L, Hayward N, Sweet A, Warner J, Marks L, Learoyd D, Dwight T, Robinson B, Epstein M, et al: A report of a national mutation testing service for the MEN1 gene: Clinical presentations and implications for mutation testing. J Med Genet 42: 69-74, 2005.

16. Teh BT, Zedenius J, Kytölä S, Skogseid B, Trotter J, Choplin H, Twigg S, Farnebo F, Giraud S, Cameron D, et al: Thymic carcinoids in multiple endocrine neoplasia type 1. Ann Surg 228: 99-105, 1998.

17. Mastroianno S, Torlontano M, Scillitani A, D'Aloiso L, Verrienti A, Bonfitto N, De Bonis A, D'Agruma L, Muscarella LA, Guarnieri V, et al: Coexistence of multiple endocrine neoplasia type 1 and type 2 in a large Italian family. Endocrine 40: 481-485, 2011.

18. Cetani F, Pardi E, Giovannetti A, Cerrai P, Borsari S, Vignali E, Picone A, Cianferotti L, Miccoli P, Pinchera A and Marcocci C: Six novel MEN1 gene mutations in sporadic parathyroid tumors. Hum Mut 16: 445, 2000.

19. Canaff L, Vanbellinghen JF, Kaji H, Goltzman D and Hendy GN: Impaired transforming growth factor- $\beta$ (TGF- $\beta$ ) transcriptional activity and cell proliferation control of a menin in-frame deletion mutant associated with multiple endocrine neoplasia type 1 (MEN1). J Biol Chem 287: 8584-8597, 2012.

20. Kelley LA, Mezulis S, Yates CM, Wass MN and Sternberg MJ: The Phyre2 web portal for protein modelling, prediction and analysis. Nat Protoc 10: 845-858, 2015. 
21. Feldman AT and Wolfe D: Tissue processing and hematoxylin and eosin staining. Methods Mol Biol 1180: 31-43, 2014.

22. Lemos MC and Thakker RV: Multiple endocrine neoplasia type 1 (MEN1): Analysis of 1336 mutations reported in the first decade following identification of the gene. Hum Mut 29: 22-32, 2008.

23. Concolino P, Costella A and Capoluongo E: Multiple endocrine neoplasia type 1 (MEN1): An update of 208 new germline variants reported in the last nine years. Cancer Genet 209: 36-41, 2016.

24. World Health Organization Classification of Tumours: Pathology and Genetics of Tumours of Endocrine Organs, 3rd edition. IARC press, 2004.

25. Schantz A and Castleman B: Parathyroid carcinoma. A study of 70 cases. Cancer 31: 600-605, 1973

26. Canaff L, Vanbellinghen JF, Kanazawa I, Kwak H, Garfield N, Vautour L and Hendy GN: Menin missense mutants encoded by the MEN1 gene that are targeted to the proteasome: Restoration of expression and activity by CHIP siRNA. J Clin Endocrinol Metab 97: E282-E291, 2012.
27. Yokoyama A, Wang Z, Wysocka J, Sanyal M, Aufiero DJ, Kitabayashi I, Herr W and Cleary ML: Leukemia proto-oncoprotein MLL forms a SET1-like histone methyltransferase complex with Menin to regulate Hox gene expression. Mol Cell Biol 24: 5639-5649, 2014

28. Campennì A, Giovinazzo S, Pignata SA, Di Mauro F, Santoro D, Curtò L, Trimarchi F, Ruggeri RM and Baldari S: Association of parathyroid carcinoma and thyroid disorders: A clinical review. Endocrine: Oct 15, 2016 (Epub ahead of print).

29. Thakker RV, Newey PJ, Walls GV, Bilezikian J, Dralle H, Ebeling PR, Melmed S, Sakurai A, Tonelli F and Brandi ML; Endocrine Society: Clinical practice guidelines for multiple endocrine neoplasia type 1 (MEN1). J Clin Endocrinol Metab 97: 2990-3011, 2012. 